\title{
Urbanization increases floral fidelity of pollinators
}

\author{
Sevan Suni ${ }^{1}$, Erin Hall ${ }^{1}$, and Evangelina Bahu ${ }^{1}$ \\ ${ }^{1}$ University of San Francisco
}

June 28, 2021

\begin{abstract}
Understanding how urbanization alters functional interactions among pollinators and plants is critically important given increasing anthropogenic land use and declines in pollinator populations. Pollinators often exhibit short-term specialization, and visit plants of the same species during one foraging trip. This facilitates plant receipt of conspecific pollen - pollen on a pollinator that is the same species as the plant on which the pollinator was foraging. Conspecific pollen receipt facilitates plant reproductive success and is thus important to plant and pollinator persistence. We investigated how urbanization affects short term specialization of insect pollinators by examining pollen loads on insects' bodies and identifying the number and species of pollen grains on insects caught in urban habitat fragments and natural areas. We then assessed possible drivers of differences between urban and natural areas, including frequency dependence in foraging, species richness and diversity of the plant and pollinator communities, floral abundance, and the presence of invasive plant species. Pollinators were more specialized in urban fragments than in natural areas, despite no differences in the species richness of plant communities across site types. These differences were likely driven by higher specialization of common pollinators, which were more abundant in urban sites. Pollinators were also more specialized when foraging on invasive plants across sites, and floral abundance of invasive plants was higher in urban sites. Our findings reveal strong effects of urbanization on pollinator fidelity to individual plant species and have implications for the maintenance of plant species diversity in small habitat fragments. The higher fidelity of pollinators to invasive plants suggests that native species may receive fewer visits by pollinators. Therefore, native plant species diversity may decline in urban sites without continued augmentation of urban flora or removal of invasive species.
\end{abstract}

\section{INTRODUCTION}

Over fifty percent of the earth's land surface has been converted for human use (Ritchie \& Roser, 2019). Given recently observed declines in pollinator populations (Goulson et al., 2015), understanding links between urbanization and plant-pollinator interactions is of increasing importance. Almost $90 \%$ of flowering plants are animal-pollinated (Ollerton et al., 2011), and one-third of crops require pollinators to produce fruit (Kearns et al., 1998). Declines have been reported in all major groups of pollinators (Regan et al., 2015), which are associated with declines in plant populations (Biesmeijer et al., 2006). While land conversion from natural to urban areas has been proposed as a major driver of pollinator decline (Bates et al., 2011; Forister et al., 2019; Hernandez et al., 2009), other work has challenged the assumption that urbanization is universally detrimental to pollinators (Baldock et al., 2015; Owen, 2010; Saure, 1996). Effects of urbanization tend to be species-specific, with some species increasing and others decreasing in abundance in urban areas (Cane et al., 2006; Matteson et al., 2008; Carre et al., 2009). This may reflect differences in the ability of individuals of certain species to exploit patchy urban floral resources, or a lack of continuously blooming flowers that result in insufficient food intake of pollinators with certain phenologies.

Given ongoing land conversion, remnant or restored natural habitat within urban areas will be increasingly important refuges of pollinator biodiversity (Goddard et al., 2010). The extent to which habitat fragments can support pollinator biodiversity depends on whether there are sufficient floral resources from which pollinators can obtain food, and whether these resources persist over time. Pollinators are expected to maximize their net energy intake while foraging (Stephens \& Krebs, 1986), and their foraging choices 
depend on the distribution of floral resources, the energetic value of those resources, and the local ecological context (MacArthur \& Pianka, 1966). Therefore, pollinator foraging choices may promote the persistence of outcrossing plants if ecological conditions facilitate pollinator transfer of conspecific pollen among plant individuals (Aguilar \& Galetto, 2004).

Plant receipt of conspecific pollen is facilitated by short-term specialization of pollinators on particular plant species. Several non-mutually exclusive mechanisms can drive short-term specialization, including flower constancy and frequency dependence in plant choice. Flower constancy occurs when pollinators forage primarily on the same plant species within a single trip (Waser, 1986; Wissel, 1977), which can be facilitated by interspecific competition (Brosi \& Briggs, 2013; Futuyma \& Moreno, 1988). Decreases in flower constancy lead to greater heterospecific pollen transfer among plants and reduced plant reproductive success (Brosi \& Briggs, 2013; Galen \& Gregory, 1989). Frequency dependence in plant choice occurs when there is a relationship between plant relative abundance and pollinator preference for that species (Krebs \& others, 1989). Pollinators have been observed to exhibit both positive and negative frequency dependence in plant choice (Rushing et al., 2006), which are thought to occur due to difficulties in efficiently foraging on multiple floral types consecutively (Chittka \& Thomson, 1997).

Optimal diet theory predicts positive frequency dependence in plant choice (MacArthur \& Pianka, 1966), but results of past examinations of plant relative abundance as a driver of pollinator foraging choices have been mixed (Eckhart et al., 2006; Schmid et al., 2016; Benadi \& Pauw, 2018). Both positive and negative frequency dependence in plant choice can drive short term specialization, but they have different effects on plant species persistence in small habitat fragments. Negative frequency dependence is predicted to lead to species coexistence, but positive frequency dependence is predicted to lead to the decline of rare species (Chesson, 2000, but see Molofsky \& Bever 2002).

Here, we test five hypotheses regarding how short-term ecological specialization of pollinators may change in urban environments. We first characterize visitation of pollinators to plants and pollen loads on pollinators' bodies, and we quantify the amount of conspecific pollen relative to heterospecific pollen carried by pollinators in natural and urban sites across a major urban in California. We then test the hypotheses that (1) the amount of conspecific pollen carried by pollinators is higher in natural sites than in urban sites; (2) pollinators exhibit positive frequency dependent foraging across site types; (3) pollinators carry more conspecific pollen at sites with less heterogeneous plant communities; (4) pollinators carry more conspecific pollen at sites with more heterogeneous pollinator communities; (5) the abundance of floral resources at a community level facilitates short-term pollinator specialization.

\section{METHODS}

\section{Field sampling $\&$ floral community characterization}

From May to August 2019 we characterized interactions between insect pollinators and plants at six natural and six urban sites in the Bay Area of California, USA (Figure S1). Urban sites were sites embedded within city limits, and contained either remnant or restored natural habitat (Table 1). Sites were designated as urban or natural using data available at https://www.bayarealands.org/maps-data along with imagery from Google Earth. Between the two points furthest from one another along the perimeter, urban sites spanned less than $4 \mathrm{~km}$, and natural areas spanned at least $60 \mathrm{~km}$ (see Figure S1). Between $10 \mathrm{am}$ and $4 \mathrm{pm}$ we used areal netting to haphazardly catch an average of 41.1 foraging insects per site (range 15-49). We targeted non-Lepidopteran insects, and obtained 493 insects on 47 plant species in total. For each plant on which a pollinator was caught, we recorded the species and sampled three anthers from one flower. At each site we also counted and recorded the species of all flowers within $15 \mathrm{~cm}$ of a $90 \mathrm{~m}$ transect, and we sampled anthers from the other flowering plants.

\section{Pollen load assessment}

We removed pollen from pollinators' bodies with Fuchsin jelly (Kearns, 1993), melted the jelly onto slides (hereafter "pollinator slides"), and visualized pollen using a light microscope. We also made slides of pollen 
from the anthers of the plant species on which each pollinator was caught (hereafter "anther slides"). We compared pollen on the anther slides to pollen on the pollinator slides to determine the number of grains that were conspecific for each pollinator. To identify heterospecific pollen to species we compared pollen on pollinator slides to pollen made from the anthers of other flowering plants at each site. We cross-referenced pollen identifications with photos from the Global Pollen Project (globalpollenproject.org).

Potential for conspecific pollen transfer

We examined the potential for conspecific pollen transfer as follows. For each pollinator, we counted the number of pollen grains that were morphologically identical to grains obtained from the anther slide on which the pollinator was caught (hereafter 'conspecific pollen grains'), from a subsample of 500 pollen grains. To do so, we began examining each slide at the upper left corner, and we recorded the species of each grain until either 500 grains were encountered $(\mathrm{N}=355$ slides) or all the pollen on the slide had been counted ( $\mathrm{N}$ $=158$ slides; Table S1). We asked how different our estimate of the proportion of conspecific grains from a subsample of 500 might be from the proportion calculated using all grains. To do so, we randomly selected 10 pollinator slides that had more than 500 total grains and counted and identified all grains (59,189 grains). The correlation of the proportion of conspecific grains estimated from the subsample of 500 grains and that estimated from all grains was 0.87 (cor.test function in $\mathrm{R} ; P<0.001$ ).

We examined if pollinators from natural sites carried a greater amount of pollen grains that were conspecific (hypothesis 1) using generalized linear mixed models with a Poisson error structure implemented using the lme4 package (Bates, 2014) in R (R Core Team, 2013). The number of conspecific grains was the dependent variable, site type (urban or natural) was the independent variable, and sampling site was a random effect. We determined if urban and natural sites differed in species diversity or richness of pollen on pollinators using linear mixed models with site type as the independent variable, and sampling site as a random effect. We used likelihood ratio tests (LR tests) to evaluate the significance of the independent variable of interest by comparing nested models with and without that factor. In the results section we report estimates from the best model chosen via backward model selection (hereafter "Est."), and the P-values from likelihood ratio tests comparing nested models.

\section{Frequency-dependent foraging}

To evaluate if pollinators exhibit positive frequency dependence in visitation (hypothesis 2), we asked if plant relative abundance predicted a metric that reflects pollinator preference (hereafter PI). We calculated PI for each species $s$ at each sampling location $p$ as in (Grüter et al., 2011):

PIs, $\mathrm{p}=\frac{P \text { obs s,p }}{(\text { Pobs s,p }+ \text { Pnull s,p })}$,

where Pobs s, $\mathrm{p}$ is the proportion of pollen grains found on pollinators at site $p$ that are species $s$, and $P$ null s, $\mathrm{p}$ is the proportion of flowers of focal plants of species $s$ among flowers of all plants in the transect. A PI value of 0 indicates no pollen from species $s$ was found on pollinators at site $p$, a value of 0.5 indicates that the observed pollen amount matches expectations based on plant relative abundance, and PIs, p approaches 1 if the amount of pollen from species $s$ is much higher than that based on plant relative abundance. For these calculations we used a dataset that included plant species that were present in transects. We tested for a relationship between preference indices and plant relative abundance using linear mixed models with preference index as the dependent variable, relative abundance as the independent variable, and site and species as random effects.

\section{Plant and pollinator community effects}

To determine if pollinators carry more conspecific pollen at sites with less heterogeneous plant communities (hypothesis 3), we characterized plant species richness, diversity, and evenness using custom $\mathrm{R}$ scripts (see data availability statement) and tested if site types differed in these metrics using t-tests. We tested if plant species richness, diversity, or evenness predicted the amount of conspecific pollen using generalized linear mixed models with a Poisson error structure and site as a random effect. To determine if pollinators carry more conspecific pollen at sites with more heterogeneous pollinator communities (hypothesis 4), we tested 
if insect species richness or diversity predicted the amount of conspecific pollen grains found on pollinators using generalized linear mixed models with a Poisson error structure and site as a random effect. To evaluate if the abundance of floral resources at a community level facilitates pollinator specialization (hypothesis 5), we quantified the total number of flowers found along each $90 \mathrm{~m}$ transect. We asked if the total number of flowers predicted conspecific pollen amount using a generalized linear mixed model with log-transformed flower number as the independent variable, site as a random effect, and a Poisson error structure.

Surprisingly, we found the opposite of what we expected regarding differences between urban and natural sites in the amount of conspecific pollen carried by pollinators (see results). Therefore, we also explored possible effects of the identities of individual plant and insect species on pollinator short-term specialization. We hypothesized that pollinators carry more conspecific pollen from invasive plants, which we predict to be in greater abundance in urban areas. To examine if plants' invasive status predicted the amount of conspecific pollen we determined if each plant on which a pollinator was caught is invasive in California using the California Invasive Plant Council Dataset, as well as theCalflora Database. We determined if site types differed in the amount of invasive plants sampled along transects, using a generalized linear mixed model a binary dependent variable that reflected if a plant was invasive or not, site type as the independent variable, site and plant species as random effects, and a binomial error structure. We tested if invasive status predicted conspecific pollen amount used invasive status as a binary independent variable in a generalized linear mixed model with average conspecific pollen amount within sites as the dependent variable, site as a random effect, and a Poisson error structure.

To evaluate if differences in conspecific pollen amount were driven by differences in the identity of the insect species found among sites, we first determined which insects were common to all or the majority of sites. Most insect species were found at five or fewer sites, with the exception of one honey bee and one bumble bee species (Apis mellifera and Bombus vosnesenskii), which were found at 10 and 11 sites, respectively. We hypothesized that if rare species were driving differences among site types, the change between urban and natural environments in the amount of conspecific pollen carried would be greater for common species. To test this hypothesis we modeled conspecific pollen amount as a function of the interaction between whether a pollinator was common or rare and site type, using a generalized linear mixed model with site as a random effect and a Poisson error structure.

\section{RESULTS}

Pollinators at urban sites carried more conspecific pollen than pollinators at natural sites $($ Est. $=0.33 ; P$ $=0.02$; Figure 1). Relative to natural sites, individual pollinators at urban sites carried pollen from fewer plant species (Est. $=-0.52 ; P=0.027$ ), and the species diversity of pollen on individual pollinators was lower in urban sites (Est. $=-0.17 ; P=0.03$ ). At the site level, urban and natural sites did not differ in the total number of plant species from which pollen was found on pollinators $(\mathrm{t}=-0.71$, $\mathrm{df}=8.1, P=0.5)$, the number of plant species on which pollinators were caught $(\mathrm{t}=0.55, \mathrm{df}=6.2, P=0.61)$, or plant species richness $(\mathrm{t}=0.87, \mathrm{df}=6.8, P=0.42)$, diversity $(\mathrm{t}=1.3, \mathrm{df}=7.2, P=0.24)$; or evenness $(\mathrm{t}=1.1, \mathrm{df}=$ $36, P=0.29$ ). Across sites, pollinators exhibited negative frequency dependent foraging, with plant relative abundance predicting pollinator preference for a given plant species (Est $=-0.34, \mathrm{P}=0.001$ ). Across sites there was an inverse relationship between conspecific pollen amount and plant species richness (Est. $=-0.057$, $P=0.0496)$, diversity (Est $=-0.38, P=0.002)$, and evenness (Est $=-0.79 ; P=0.013$ ).

Urban sites had lower insect species richness than natural sites (mean urban $=2.8 ;$ mean natural $=7.5 ; \mathrm{t}$ $=-3.5, \mathrm{df}=8.3, P=0.008)$. Urban sites also had lower insect species diversity than natural sites $(\mathrm{t}=-3.9$, $\mathrm{df}=9.0, P=0.0036)$. However, the amount of conspecific pollen was predicted neither by insect species richness (Est. $=-0.029 ; P=0.26)$ nor species diversity $($ Est $=-0.22, P=0.11$ ).

Floral abundance at the site level was positively associated with the amount of conspecific pollen (Est $=$ $0.13, P=0.0014)$, and the number of flowers per plant was higher in urban areas (Est. $=1.8, P=0.046$ ). Urban sites also tended to have a higher total number of flowers but this trend was not significant (Est. $1.5, P=0.06$ ). There was substantial variation among sites in the species richness of invasive plants (Table 
1). Urban sites contained fewer invasive plant individuals (Est. $=-1.6, P=0.028$ ), but contained more flowers from invasive plants (Est. 1.2, $P<0.001$ ). Furthermore, the increase in the number of flowers per plant individual in urban sites was greater for invasive plants (Interaction est. = 1.2, $\mathrm{P}<0.001$; Figure S2). Pollinators carried more conspecific pollen when caught on invasive plants in both types of sites (Est $=0.07$, $P<0.001$; Figure 2), and the difference in conspecific pollen amount between urban and natural sites was lower for invasive plants (Interaction est. $=-0.058 ; P<0.001$ ).

Common pollinators comprised a greater amount of the pollinator community at urban sites than at natural sites (Est $=4.7, P<0.001)$. Differences between urban and natural sites in the amount of conspecific pollen carried by pollinators was different for common and rare pollinators. Common pollinators carried more conspecific pollen than rare pollinators (Est. $=0.38 ; P<0.001$ ), and the increase in the amount of conspecific pollen carried in urban environments was greater for common pollinators (Interaction est. $=0.12$; $P<0.001 ;$ Figure S3).

\section{DISCUSSION}

The greater amount of conspecific pollen on pollinators from urban areas suggests those pollinators exhibit greater short-term foraging specialization than pollinators in natural sites. This finding was corroborated by the higher species richness and diversity of pollen on pollinators from natural sites, suggesting that pollinators in natural sites visit more plant species during foraging trips. Finding greater specialization among urban pollinators was contrary to our hypothesis based on ecological theory that greater interspecific competition leads to greater species-level specialization in resource use (Lawlor \& Smith, 1976). As expected, urban sites had lower insect species richness, but this did not translate into lower specialization. On the contrary, we found no relationship between insect species richness and specialization. A possible reason for the discrepancy with theory is that the lower specialization we found in natural areas could result from effects of species richness on interspecific competition being mediated by pollinator abundance. Total abundance of pollinator species in our study sites is unknown, but it is plausible that even in cases where species richness is high, low species evenness could prevent interspecific competition from driving short term specialization.

Among the possible drivers of short-term specialization examined in this study, we found several that may have acted synergistically to cause urban pollinators to carry higher amounts of conspecific pollen than pollinators from natural sites. First, total floral abundance of the plant community was positively associated with higher conspecific pollen amount, and the number of flowers per plant species was greater in urban areas. Since there was no difference in plant species richness between site types, it follows that pollinators would carry more conspecific pollen in urban areas. Why might total floral abundance at the site level predict conspecific pollen amount on individual pollinators? Most pollinators do not have fixed affinities for certain plants (Waser et al., 1996) and will continue to forage on flowers of particular species when those flowers are sufficiently rewarding that travel costs incurred by passing up flowers of less abundant species are low (Heinrich, 1979; Waser, 1986). In addition, pollinators spend longer on flowers if there is more, or higher quality nectar present (Thomson, 1986), which might facilitate the accumulation of more pollen. In contrast, pollinators are more likely to switch plant species when they consistently encounter flowers of a particular species that are rewardless (Grüter et al., 2011). It is possible that pollinators experience rewarding flowers more often than pollinators at natural sites because of the higher number of flowers in urban sites. It is also possible that floral reward is greater in urban sites due to an overall lower abundance of pollinators, or more favorable ecological conditions such as moisture levels that promote production of more flowers or flowers with greater rewards. Moisture levels are higher in the urban sites used in this study (Tables S2-S4; Figure S4), so investigating whether the higher water availability translates into higher floral reward in urban sites would thus be worthwhile.

Second, common pollinators were more specialized at urban sites than at natural sites. Relative to natural sites, average conspecific pollen amounts increased by $54 \%$ and $23 \%$ for A. mellifera and B. vosnesenskii in urban sites. The increase in specialization of these common species coupled with their greater abundance at urban sites likely contributed to the higher conspecific pollen amounts found on pollinators at urban sites. Third, pollinators carried more conspecific pollen when caught on invasive plants, and floral abundance 
of invasive plants was higher than that of non-invasive plants in urban areas. Therefore, the preferential foraging on flowers of invasive species likely led to the greater conspecific pollen amounts on pollinators in urban sites. The high amounts of conspecific pollen on pollinators foraging on invasive plants suggests that pollinators exhibit high fidelity to invasive plant species in our urban sites. As for all plant species, pollinator preference for invasive plants is context specific, and tends to depend on the size of floral display, quality of food resources, or plant density (Brown et al., 2002; King \& Sargent, 2012). The most common invasive species across sites in our data set were Wild Radish (Raphanus raphanistrum), Wild Mustard (Sinapis arvensis ), and Hairy Vetch (Vicia villosa). Each of these tend to be present at high densities and have high amounts of nectar or pollen reward (Davis et al., 1998; Marchand et al., 2015; Sahli \& Conner, 2007). Our finding that pollinators have higher floral fidelity to invasive species motivates future research into how floral reward or plant density may differ between native and invasive plants and how these differences may influence pollinator choices in urban environments.

Another potential driver that may contribute to the higher specialization we observed for urban pollinators is the amount of energy pollinators may need to spend acquiring sufficient resources in different environments. The importance of pollinator movement to the acquisition of sufficient resources is largely unknown (Harrison \& Winfree, 2015), but pollinators have been observed to spend longer amounts of time in urban flower patches than in large continuous countryside populations (Andrieu et al., 2009). Urban landscapes are characterized by large regions of inhospitable habitat over which pollinators may need to travel to reach food resources. This longer time spent in urban fragments presumably allows pollinators to recoup energetic costs of travel among patches. After arriving in an urban patch, pollinators may be likely to continue foraging on the same species of plant and not expend energy learning to manipulate alternative floral types. The extent to which pollinators move among urban fragments in our study area would be a valuable future research direction.

Our findings have implications for plant species coexistence both in urban and natural areas. On the one hand, the negative frequency dependence in pollinator preference suggests a mechanism by which plant species may coexist with one another and persist in urban fragments. On the other hand, pollinator preference for invasive species may facilitate invasive plant spread and loss of rare native plant species. Many studies have reported positive relationships between urbanization and invasive plant abundance (Bradley \& Mustard, 2006; George et al., 2009; Seabloom et al., 2006). Our results highlight a mechanism that may underlie this pattern, whereby pollinator fidelity to invasive plants facilitates their persistence in urban environments. Our results also suggest that pollinator foraging choices may facilitate invasive plant spread in natural areas. Pollinators were even more specialized when they were caught foraging on invasive plants in natural environments than they were when caught foraging on invasive plants in urban environments. The fidelity to invasive plants, in both urban and natural areas, suggests that rare native plant species may receive many fewer visits by pollinators than common, invasive species. This may be particularly problematic for the persistence of rarer native plants in urban areas that are present at low abundance. Urban pollinators caught on native plants still carried on average $53 \%$ conspecific pollen, but this percent dropped to $42 \%$ for native plants that were present at less than $20 \%$ frequency, and it dropped to $29 \%$ for plants that were present at a frequency of $10 \%$ at the study sites. These decreases the proportion of conspecific pollen with increasing rarity of native plants suggest that continued augmentation of urban flora, along with removal of invasive species may therefore be necessary to maintain plant species diversity at these sites.

To our knowledge this is the first study that quantifies conspecific and heterospecific pollen carriage of pollinators in natural and urban sites. The conspecific pollen proportions found on pollinators suggest there is a greater potential for conspecific pollen transfer among plants in urban areas than in natural areas. It is worth noting that we did not explicitly measure flower constancy, so we cannot know if pollinators moved among flowers of the same individual plant or among flowers of different individuals. Self-incompatible plants cannot produce seeds unless they receive pollen from a different conspecific individual (Castric \& Vekemans, 2004). Therefore, it will be worthwhile to explore whether the greater conspecific pollen proportions found on urban pollinators are reflective of visits to single plant individuals or several different plants of the same species. 


\section{DATA AVAILABILITY STATEMENT}

Data and custom scripts are available on Zenodo.com (DOI: 10.5281/zenodo.4605553).

\section{ACKNOWLEDGEMENTS}

We thank I. Bamba, D. Celedonio, B. Finney, and J. Paulino for help with data collection, H. Hayes for help with insect identification, and N. Zimmerman for help with data manipulation. This work was supported by the University of San Francisco's Faculty Development Fund.

\section{AUTHOR CONTRIBUTIONS}

SS and EH conceived of the ideas and designed the study; SS, EH, and EB collected the data and refined the methodology; SS analyzed the data and wrote the manuscript with critical input from EH and EB.

\section{REFERENCES}

Aguilar, R., \& Galetto, L. (2004). Effects of forest fragmentation on male and female reproductive success in cestrum parqui (solanaceae).Oecologia , 138 (4), 513-520.

Andrieu, E., Dornier, A., Rouifed, S., Schatz, B., \& Cheptou, P.-O. (2009). The town crepis and the country crepis: How does fragmentation affect a plant-pollinator interaction? Acta Oecologica ,35 (1), 1-7.

Baldock, K. C., Goddard, M. A., Hicks, D. M., Kunin, W. E., Mitschunas, N., Osgathorpe, L. M., .. others. (2015). Where is the uk's pollinator biodiversity? The importance of urban areas for flower-visiting insects. Proceedings of the Royal Society B: Biological Sciences , 282 (1803), 20142849.

Bates, A. J., Sadler, J. P., Fairbrass, A. J., Falk, S. J., Hale, J. D., \& Matthews, T. J. (2011). Changing bee and hoverfly pollinator assemblages along an urban-rural gradient. PloS One, 6 (8), e23459.

Bates, D., Mächler, M., Bolker, B., \& Walker, S. (2014). Fitting linear mixed-effects models using lme4. arXiv Preprint arXiv:1406.5823 .

Benadi, G., \& Pauw, A. (2018). Frequency dependence of pollinator visitation rates suggests that pollination niches can allow plant species coexistence. Journal of Ecology , 106 (5), 1892-1901.

Biesmeijer, J. C., Roberts, S. P., Reemer, M., Ohlemüller, R., Edwards, M., Peeters, T., et al. (2006). Parallel declines in pollinators and insect-pollinated plants in britain and the netherlands. Science ,313 (5785), 351354.

Bradley, B. A., \& Mustard, J. F. (2006). Characterizing the landscape dynamics of an invasive plant and risk of invasion using remote sensing.Ecological Applications , 16 (3), 1132-1147.

Brosi, B. J., \& Briggs, H. M. (2013). Single pollinator species losses reduce floral fidelity and plant reproductive function.Proceedings of the National Academy of Sciences , 110 (32), 13044-13048.

Brown, B. J., Mitchell, R. J., \& Graham, S. A. (2002). Competition for pollination between an invasive species (purple loosestrife) and a native congener. Ecology , 83 (8), 2328-2336.

Cane, J. H., Minckley, R. L., Kervin, L. J., Roulston, T. H., \& Williams, N. M. (2006). Complex responses within a desert bee guild (hymenoptera: Apiformes) to urban habitat fragmentation.Ecological Applications , $16(2), 632-644$.

Carre, G., Roche, P., Chifflet, R., Morison, N., Bommarco, R., Harrison-Cripps, J., . . others. (2009). Landscape context and habitat type as drivers of bee diversity in european annual crops.Agriculture, Ecosystems E Environment , 133 (1-2), 40-47.

Castric, V., \& Vekemans, X. 2004 Invited review: Plant self-incompatibility in natural populations: A critical assessment of recent theoretical and empirical advances. Molecular Ecology13 , 2873-2889. 
Chesson, P. (2000). Mechanisms of maintenance of species diversity. Annual Review of Ecology and Systematics , 31 (1), 343-366.

Chittka, L., \& Thomson, J. D. (1997). Sensori-motor learning and its relevance for task specialization in bumble bees. Behavioral Ecology and Sociobiology , 41 (6), 385-398.

Davis, A. R., Pylatuik, J. D., Paradis, J. C., \& Low, N. H. (1998). Nectar-carbohydrate production and composition vary in relation to nectary anatomy and location within individual flowers of several species of brassicaceae. Planta, 205 (2), 305-318.

Forister, M. L., Pelton, E. M., \& Black, S. H. (2019). Declines in insect abundance and diversity: We know enough to act now. Conservation Science and Practice, 1 (8), e80.

Futuyma, D. J., \& Moreno, G. (1988). The evolution of ecological specialization. Annual Review of Ecology and Systematics ,19 (1), 207-233.

Galen, C., \& Gregory, T. (1989). Interspecific pollen transfer as a mechanism of competition: Consequences of foreign pollen contamination for seed set in the alpine wildflower, polemonium viscosum.Oecologia , 81 (1), 120-123.

George, K., Ziska, L. H., Bunce, J. A., Quebedeaux, B., Hom, J. L., Wolf, J., \& Teasdale, J. R. (2009). Macroclimate associated with urbanization increases the rate of secondary succession from fallow soil. Oecologia , 159 (3), 637-647.

Goddard, M. A., Dougill, A. J., \& Benton, T. G. (2010). Scaling up from gardens: Biodiversity conservation in urban environments. Trends in Ecology \&5 Evolution , 25 (2), 90-98.

Goulson, D., Nicholls, E., Botías, C., \& Rotheray, E. L. (2015). Bee declines driven by combined stress from parasites, pesticides, and lack of flowers. Science, 347 (6229), 1255957.

Grüter, C., Moore, H., Firmin, N., Helanterä, H., \& Ratnieks, F. L. (2011). Flower constancy in honey bee workers (apis mellifera) depends on ecologically realistic rewards. Journal of Experimental Biology, 214 (8), 1397-1402.

Harrison, T., \& Winfree, R. (2015). Urban drivers of plant-pollinator interactions. Functional Ecology , 29 (7), 879-888.

Heinrich, B. (1979). Resource heterogeneity and patterns of movement in foraging bumblebees. Oecologia, $40(3), 235-245$.

Hernandez, J. L., Frankie, G. W., \& Thorp, R. W. (2009). Ecology of urban bees: A review of current knowledge and directions for future study. Cities and the Environment (CATE) , 2 (1), 3.

Kearns, C. A., Inouye, D. W., \& others. (1993). Techniques for pollination biologists . University press of Colorado.

Kearns, C. A., Inouye, D. W., \& Waser, N. M. (1998). Endangered mutualisms: The conservation of plantpollinator interactions.Annual Review of Ecology and Systematics , 29 (1), 83-112.

King, V. M., \& Sargent, R. D. (2012). Presence of an invasive plant species alters pollinator visitation to a native. Biological Invasions , 14 (9), 1809-1818.

Krebs, C. J., \& others. (1989). Ecological methodology . Harper \& Row New York.

Lawlor, L. R., \& Smith, J. M. (1976). The coevolution and stability of competing species. The American Naturalist , 110 (971), 79-99.

M. Eckhart, V., S. Rushing, N., M. Hart, G., \& D. Hansen, J. (2006). Frequency-dependent pollinator foraging in polymorphic clarkia xantiana ssp. xantiana populations: Implications for flower colour evolution and pollinator interactions. Oikos , 112 (2), 412-421. 
MacArthur, R. H., \& Pianka, E. R. (1966). On optimal use of a patchy environment. The American Naturalist , 100 (916), 603-609.

Marchand, P., Harmon-Threatt, A. N., \& Chapela, I. (2015). Testing models of bee foraging behavior through the analysis of pollen loads and floral density data. Ecological Modelling , 313 , 41-49.

Molofsky, J., \& Bever, J. D. (2002). A novel theory to explain species diversity in landscapes: Positive frequency dependence and habitat suitability. Proceedings of the Royal Society of London. Series B: Biological Sciences , 269 (1508), 2389-2393.

Ollerton, J., Winfree, R., \& Tarrant, S. (2011). How many flowering plants are pollinated by animals? Oikos , $120(3), 321-326$.

Owen, J. (2010). Wildlife of a garden: A thirty-year study . Royal Horticultural Society.

Regan, E. C., Santini, L., Ingwall-King, L., Hoffmann, M., Rondinini, C., Symes, A., ... Butchart, S. H. (2015). Global trends in the status of bird and mammal pollinators. Conservation Letters ,8 (6), 397-403.

Ritchie, H., \& Roser, M. (2019). Land use. Our World in Data .

Sahli, H. F., \& Conner, J. K. (2007). Visitation, effectiveness, and efficiency of 15 genera of visitors to wild radish, raphanus raphanistrum (brassicaceae). American Journal of Botany ,94 (2), 203-209.

Saure, C. (1996). Urban habitats for bees: The example of city of berlin. The Conservation of Bees .

Schmid, B., Nottebrock, H., Esler, K., Pagel, J., Böhning-Gaese, K., Schurr, F., .. Schleuning, M. (2016). A bird pollinator shows positive frequency dependence and constancy of species choice in natural plant communities. Ecology, 97 (11), 3110-3118.

Seabloom, E. W., Williams, J. W., Slayback, D., Stoms, D. M., Viers, J. H., \& Dobson, A. P. (2006). Human impacts, plant invasion, and imperiled plant species in california. Ecological Applications ,16 (4), 1338-1350.

Stephens, D. W., \& Krebs, J. R. (1986). Foraging theory (Vol. 1). Princeton University Press.

Team, R. C., \& others. (2013). R: A language and environment for statistical computing .

Thomson, J. D. (1986). Pollen transport and deposition by bumble bees in erythronium: Influences of floral nectar and bee grooming. The Journal of Ecology , 329-341.

Waser, N. M. (1986). Flower constancy: Definition, cause, and measurement. American Naturalist, 593-603.

Waser, N. M., Chittka, L., Price, M. V., Williams, N. M., \& Ollerton, J. (1996). Generalization in pollination systems, and why it matters.Ecology, 77 (4), 1043-1060.

Wissel, C. (1977). On the advantage of the specialization of flowers on particular pollinator species. Journal of Theoretical Biology ,69 (1), 11-22.

\begin{tabular}{|c|c|c|c|c|c|c|c|c|c|c|c|}
\hline Site & Type & Date & $\mathrm{N}$ & $\begin{array}{l}\text { Plant } \\
\text { SR }\end{array}$ & $\begin{array}{l}\text { Plant } \\
\text { SD }\end{array}$ & $\begin{array}{l}\text { Inv. } \\
\text { SR }\end{array}$ & $\begin{array}{l}\text { Inv. } \\
\text { for. }\end{array}$ & $\begin{array}{l}\text { Insect } \\
\text { SR }\end{array}$ & $\begin{array}{l}\text { Insect } \\
\text { SD }\end{array}$ & $\begin{array}{l}\text { Pollen } \\
\text { SR } \\
\text { (avg.) }\end{array}$ & $\begin{array}{l}\text { Pollen } \\
\text { SD } \\
\text { (avg.) }\end{array}$ \\
\hline $\mathrm{AZ}$ & $\mathrm{N}$ & $5 / 22 / 19$ & 46 & 6 & 1.3 & 0 & 0 & 6 & 1.3 & 3.1 & 0.58 \\
\hline $\mathrm{BO}$ & $\mathrm{N}$ & $5 / 30 / 19$ & 15 & 8 & 1.8 & 5 & 9 & 5 & 1.4 & 2.5 & 0.54 \\
\hline $\mathrm{HH}$ & $\mathrm{U}$ & $8 / 8 / 19$ & 48 & 11 & 2.1 & 2 & 0 & 2 & 0.68 & 2.2 & 0.42 \\
\hline $\mathrm{LE}$ & $\mathrm{U}$ & $5 / 28 / 19$ & 36 & 4 & 0.93 & 1 & 36 & 7 & 1.2 & 1.9 & 0.35 \\
\hline LM & $\mathrm{U}$ & $6 / 4 / 19$ & 49 & 4 & 0.89 & 2 & 6 & 3 & 0.75 & 2.4 & 0.49 \\
\hline $\mathrm{MB}$ & $\mathrm{N}$ & $6 / 17 / 19$ & 48 & 6 & 1.2 & 5 & 42 & 9 & 1.2 & 2.2 & 0.64 \\
\hline MH & $\mathrm{N}$ & $6 / 10 / 19$ & 24 & 4 & 0.96 & 3 & 32 & 5 & 1.1 & 2.7 & 0.63 \\
\hline MS & $\mathrm{U}$ & $6 / 26 / 19$ & 49 & 7 & 0.97 & 3 & 1 & 3 & 0.36 & 2.2 & 0.40 \\
\hline $\mathrm{PO}$ & $\mathrm{U}$ & $7 / 10 / 19$ & 47 & 2 & 0.67 & 1 & 24 & 1 & 0 & 1.7 & 0.48 \\
\hline
\end{tabular}




\begin{tabular}{|c|c|c|c|c|c|c|c|c|c|c|c|}
\hline Site & Type & Date & $\mathrm{N}$ & $\begin{array}{l}\text { Plant } \\
\text { SR }\end{array}$ & $\begin{array}{l}\text { Plant } \\
\text { SD }\end{array}$ & $\begin{array}{l}\text { Inv. } \\
\text { SR }\end{array}$ & $\begin{array}{l}\text { Inv. } \\
\text { for. }\end{array}$ & $\begin{array}{l}\text { Insect } \\
\text { SR }\end{array}$ & $\begin{array}{l}\text { Insect } \\
\text { SD }\end{array}$ & $\begin{array}{l}\text { Pollen } \\
\text { SR } \\
\text { (avg.) }\end{array}$ & $\begin{array}{l}\text { Pollen } \\
\text { SD } \\
\text { (avg.) }\end{array}$ \\
\hline$\overline{\mathrm{RM}}$ & $\mathrm{U}$ & $8 / 14 / 19$ & 33 & 2 & 0.06 & 0 & 0 & 2 & 0.1 & 1.4 & 0.06 \\
\hline $\mathrm{RS}$ & $\mathrm{N}$ & $6 / 12 / 19$ & 49 & 6 & 1.0 & 5 & 5 & 11 & 2.0 & 2.1 & 0.34 \\
\hline $\mathrm{SR}$ & $\mathrm{N}$ & $6 / 5 / 19$ & 49 & 8 & 1.6 & 7 & 32 & 10 & 1.5 & 2.0 & 0.51 \\
\hline
\end{tabular}

Table 1: For each site, whether it was embedded within an urban area (U) or was part of a large tact of natural land $(\mathrm{N})$, the date sampled, number of pollinator samples obtained $(\mathrm{N})$, the species richness (SR) and Shannon-Weiner Diversity (SD) of plant species growing at sites as assessed with transects, the species richness of invasive plants on transects (Inv. SR), the number of pollinators that were foraging on invasive plants (Inv. for.), the species richness (SR) and Shannon-Weiner Diversity (SD) of pollinator species and plant species from which pollen was found on pollinators (averaged over pollinators), and the total number of plant species from which pollen was found across all pollinators (tot).

\section{Hosted file}

image1.emf available at https://authorea.com/users/422361/articles/528082-urbanizationincreases-floral-fidelity-of-pollinators

Figure 1. The average proportion of conspecific pollen found on pollinators across the 12 sites. Error bars represent standard errors of the mean. Colors reflect site types, with green representing natural sites and grey representing urban sites.

\section{Hosted file}

image2.emf available at https://authorea.com/users/422361/articles/528082-urbanizationincreases-floral-fidelity-of-pollinators

Figure 2. The proportion of conspecific pollen carried by pollinators that were caught when foraging on invasive or non-invasive plants, averaged across sites within each site type (urban or natural). Dark gray represents pollen proportions on pollinators foraging on non-invasive plants, while light gray represents pollen proportions on pollinators foraging on non-invasive plants. Errors represent standard errors of the mean. 